\title{
Antidepressant exposure in pregnancy and risk of autism spectrum disorders
}

This article was published in the following Dove Press journal:

Clinical Epidemiology

14 November 2013

Number of times this article has been viewed

\section{Merete Juul Sørensen' \\ Therese Koops Grønborg² \\ Jakob Christensen ${ }^{3,4}$ \\ Erik Thorlund Parner ${ }^{2}$ \\ Mogens Vestergaard ${ }^{5,6}$ \\ Diana Schendel ${ }^{7}$ \\ Lars Henning Pedersen 8,9}

'Regional Centre of Child and Adolescent Psychiatry, Aarhus University Hospital, Risskov, Denmark; ${ }^{2}$ Department of Public Health, Section of Biostatistics, Aarhus University, Aarhus, Denmark; ${ }^{3}$ Department of Neurology, Aarhus University Hospital, Aarhus,

Denmark; ${ }^{4}$ Department of Clinical Pharmacology, ${ }^{5}$ Department of Public Health, Section of General Practice, ${ }^{6}$ Research unit for General Practice, Aarhus University, Aarhus, Denmark; ${ }^{7}$ Centers for Disease Control and Prevention, Atlanta, GA, USA; ${ }^{8}$ Danish Epidemiological Science Centre, Institute of Public Health, ${ }^{9}$ Department of Obstetrics and Gynecology, Institute of Clinical Medicine, Aarhus University, Aarhus, Denmark
Correspondence: Merete Juul Sørensen Regional Centre of Child and Adolescent Psychiatry, Department C, Skovagervej 2, DK-8240, Risskov, Denmark

Tel +45784731 I 8

Fax +45 7789 4I 99

Email meresoer@rm.dk
Background: Both the use of antidepressant medication during pregnancy and the prevalence of autism spectrum disorder have increased during recent years. A causal link has recently been suggested, but the association may be confounded by the underlying indication for antidepressant use. We investigated the association between maternal use of antidepressant medication in pregnancy and autism, controlling for potential confounding factors.

Methods: We identified all children born alive in Denmark 1996-2006 $(n=668,468)$ and their parents in the Danish Civil Registration System. We obtained information on the mother's prescriptions filled during pregnancy from the Danish National Prescription Registry, and on diagnoses of autism spectrum disorders in the children and diagnoses of psychiatric disorders in the parents from the Danish Psychiatric Central Register. In a cohort analysis, we estimated hazard ratios of autism spectrum disorders in children exposed to antidepressant medication during pregnancy compared with children who were not exposed, using Cox proportional hazards regression analysis. Furthermore, we estimated the risk for autism spectrum disorder in a sibling design.

Results: Children exposed prenatally to antidepressants had an adjusted hazard ratio of 1.5 (95\% confidence interval [CI] 1.2-1.9) for autism spectrum disorder compared with unexposed children. Restricting the analysis to children of women with a diagnosis of affective disorder, the adjusted hazard ratio was 1.2 (95\% CI 0.7-2.1), and the risk was further reduced when exposed children were compared with their unexposed siblings (adjusted hazard ratio 1.1; 95\% CI 0.5-2.3).

Conclusion: After controlling for important confounding factors, there was no significant association between prenatal exposure to antidepressant medication and autism spectrum disorders in the offspring.

Keywords: antidepressants, depression; autism, autism spectrum disorder, childhood autism, pregnancy

\section{Introduction}

Rates of antidepressant use during pregnancy have increased during recent years, ${ }^{1}$ and studies indicate that $1 \%-8 \%$ of pregnant women receive antidepressant medication. ${ }^{2-5}$ Some studies find that prenatal exposure to antidepressants is associated with adverse outcomes in the offspring, in areas such as motor development ${ }^{6,7}$ and neonatal adaptation, ${ }^{8-10}$ and an increased occurrence of congenital heart malformations. ${ }^{11}$ However, other studies find no association between prenatal exposure to antidepressants and internalizing ${ }^{12}$ or externalizing ${ }^{13}$ symptoms, cognitive development ${ }^{14,15}$ or congenital $^{1}$ malformations in the child. ${ }^{16,17}$ Rates of autism spectrum disorders (ASD) are increasing, ${ }^{18,19}$ but the underlying causal pathway is unclear. Both genetic and environmental factors are likely to play an important role. ${ }^{20}$ ASD risk factors associated with the 
intrauterine environment such as maternal smoking during pregnancy, ${ }^{21}$ maternal infections and inflammation, ${ }^{22,23}$ and prenatal exposure to antiepileptic medication ${ }^{24}$ have been suggested. It has been hypothesized that increased serotonergic activity during brain development may increase the risk of autism, ${ }^{25,26}$ and two recent epidemiologic studies link prenatal exposure to selective serotonin reuptake inhibitor (SSRI) use with ASD. ${ }^{27,28} \mathrm{~A}$ limitation, acknowledged in both of these epidemiologic studies, is that a parental psychiatric disorder in itself is associated with increased risk of autism in the offspring, and the suggested drug effect could therefore be a consequence of the underlying maternal disease rather than of the treatment. ${ }^{29,30}$ Discontinuation of antidepressant medication during pregnancy, however, carries an increased risk for relapse of depression, ${ }^{31}$ with known risks for the mother, as well as for the child. ${ }^{32,33}$

We conducted a large population-based cohort study to investigate the association between maternal use of antidepressant medication during pregnancy and ASD in the offspring, adjusting for potential confounding factors. To further distinguish the effect of antidepressant medication from an underlying disease, we examined the association between paternal use of antidepressants and risk of ASD in the offspring; we also studied the risk of ASD in siblings discordant for prenatal antidepressant exposure.

\section{Methods}

Registry data sources

\section{and study population}

We identified all children born alive in Denmark between January 1, 1996 and December 31, 2006 in the Danish Civil Registration System (CRS). ${ }^{34}$ The CRS contains information about the personal identification number - the CRS numberthat is assigned to all persons having permanent residence in Denmark. The CRS also contains information on sex, date of birth, death, immigration status, maternal identity, paternal identity if known, and sibling identity. The CRS number allows linkage of individual information from the CRS with information from a range of other national registries. We obtained information on age, sex, and family relations from the CRS, and we used the CRS number to link individual information from all national registries used in the study.

The Danish National Prescription Registry (DNPR) ${ }^{35}$ holds information on prescriptions filled since January 1, 1996, written by a general practitioner or medical specialist. We obtained information on maternal and paternal use of medication from the DNPR. The Danish Psychiatric Central Register (DPCR $)^{36}$ includes diagnoses from all in-patient and out-patient psychiatric hospital-based units in Denmark, but not from general practitioners, or private specialists. We used the DPCR to obtain diagnostic information on children and their parents in the study. The Danish Medical Birth Registry ${ }^{37}$ contains information on all newborns; we obtained information about gestational age, parity, and birth weight from this register. The Danish National Hospital Register $(\mathrm{DNHR})^{38}$ has collected nationwide data on all somatic hospital admissions since 1977 and includes data on outpatients since 1995; we obtained diagnostic information about congenital malformations from the DNHR.

Based on the linked registry data, our study population included children with an estimated time of conception after February 1, $1996(n=668,468)$. We excluded children with missing $(n=6,275 ; 0.9 \%)$ or extreme values of gestational age ( $\leq 23$ weeks and $\geq 45$ weeks) $(n=1,489 ; 0.2 \%)$, missing information about the mother $(\mathrm{n}=5 ; 0.001 \%)$, adopted children $(n=3,461 ; 0.5 \%)$, and children who died during the first year of life $(n=1,623 ; 0.2 \%)$. Children who died later than one year after birth $(n=40 ; 0.01 \%)$ and children who emigrated $(n=14,492$; $2.2 \%$ ) were censored at time of death or emigration.

\section{Medication exposure}

We defined the exposure window from 30 days before conception to the day of birth and included all antidepressant prescriptions filled from January 1, 1996 to December 31, 2006. We defined users of antidepressants as women who filled a prescription for antidepressant medication during the exposure window with the Anatomical Therapeutic Chemical code N06A (antidepressant drugs). We specifically assessed prescriptions of three, not mutually exclusive, subgroups of antidepressants: SSRIs; serotonin-norepinephrine reuptake inhibitors (SNRIs); and tricyclic antidepressants (TCA) (Figure 1). We did not include information about medication other than antidepressants. We estimated the average daily dose of antidepressants from the total amount of antidepressant drugs filled divided by the number of days during the exposure window, and dichotomized the average daily dose into the upper $50 \%$ and the lower $50 \%$ based on the defined daily dose of the individual drug. ${ }^{39}$

We dichotomized exposed women into those who filled a prescription for antidepressant medication from 30 days before pregnancy until the end of the first trimester and those who filled a prescription for antidepressants only later in pregnancy.

\section{Outcome information}

In the DPCR, we identified children who had been diagnosed with ASD or childhood autism (CA) by December 6, 2010 


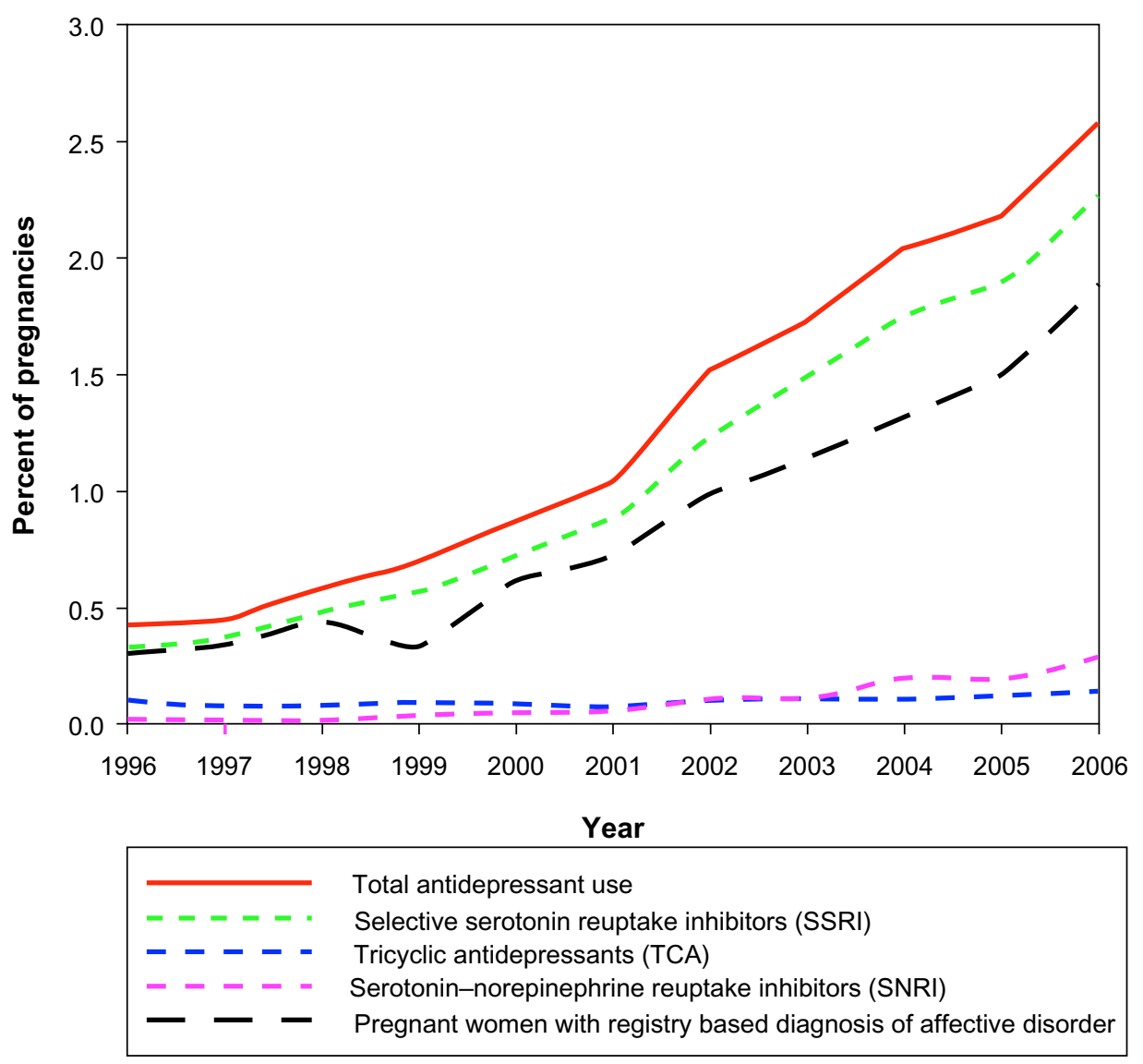

Figure I Use of SSRIs (selective serotonin reuptake inhibitors), SNRIs (serotonin-norepinephrine reuptake inhibitors), and TCAs (tricyclic antidepressants) over time in pregnancies.

based on the International Statistical Classification of Diseases and Related Health Problems (ICD)-10 (codes F84.0, F84.1, F84.5, F84.8, and F84.9). Diagnoses are reported to the DPCR from Danish child and adolescent psychiatric clinics. The Danish public health services are free of charge, and children suspected of having ASD will usually be referred for assessment at a hospital-based outpatient child and adolescent psychiatry clinic, where clinical assessment is made by a specialized team including child psychiatrists and psychologists. The quality of the infantile autism diagnosis in the DPCR has been validated by Lauritsen et al. ${ }^{40}$ After evaluating 499 medical records of children diagnosed with childhood autism using the ICD-10, 94\% $(n=469)$ met the criteria for correct diagnosis.

\section{Covariate information}

In the DPCR, we identified parents diagnosed with a history of an affective disorder such as unipolar depression or bipolar affective disorder (specifically, ICD-8 codes 296.09, 296.19, 296.29, 296.39, 296.99, 298.09, 298.19, 300.49, and 301.19, and ICD-10 codes F30-F34 and F38-F39), as well as parents with a history of any psychiatric diagnosis (ICD-8 codes 290-315 and ICD-10 codes F0.00-F99.9) before birth of the indexed child.

We identified children with congenital malformations using ICD-10 codes Q0-Q99; two diagnoses of malformations with known low validity in the DNHR were not included in this category, Q53 (undescended testicle) and Q65 (congenital deformities of hip). ${ }^{41}$

\section{Analytic approach}

We estimated the overall prevalence of ASD, CA, antidepressant use, and affective disorder in the mother using Kaplan-Meier product-limit method (Stata 11.1; StataCorp LP, College Station, TX, USA). The hazard ratio (HR) for ASD and CA associated with antidepressant drug exposure was estimated by Cox proportional hazards regression analysis, with age of the child as the underlying time scale and separate baseline diagnostic rates (strata) for each birth year group to account for changing rates of ASD over time. HRs were adjusted (adjusted HR/aHR) for parental age at conception ( $<21$ years, 21-25 years, 26-30 years, 31-35 years, $>36$ years); parental psychiatric history at birth 
(yes, no); gestational age ( $<28$ weeks, 28-31 weeks, 32-26 weeks, $>37$ weeks); birth weight $(<2,500 \mathrm{~g}, 2,500-2,999 \mathrm{~g}$, 3,000-3,499 g, >3,500 g); child's sex (boy, girl); and parity $(0,>1)$ (Table 1$)$. The proportional hazards assumption was evaluated for all variables by comparing estimated logminus-log survivor curves over the different categories of variables that we investigated. Since analyses were stratified by maternal affective disorder, this disorder was excluded from the parental psychiatric history at birth variable, except in the analyses stratified by paternal affective disorder. In the latter analyses, paternal affective disorder was excluded from the parental psychiatric history at birth variable. Only HRs for analyses that included at least five observed cases are presented (Tables 2-5). The Spearman correlation coefficient was used to analyze the correlation between the father's and mother's use of antidepressant medication. In the main analysis, the overall aHR for ASD and CA were estimated for children exposed to any antidepressant.

Sensitivity analyses included repetition of the main analysis, but 1) excluded children with congenital birth defects; 2) included only women who filled more than one prescription during pregnancy; and 3) extended the exposure window to 60,90 , and 180 days before pregnancy.

In subanalyses, the aHR for ASD and CA were estimated for major subgroups of antidepressants (SSRI, TCA, and SNRI). Further subanalyses included: estimation of aHRs for ASD and CA after exposure to high and low dose levels; and aHRs for ASD and CA for children exposed in the first trimester and late in pregnancy to both any antidepressant, and specifically to SSRI.

We applied the following three analytic strategies to further adjust for confounding by indication. In Model 1, we calculated the aHR for ASD and CA for exposed children, including only children of women with a prepregnancy registry-based diagnosis of affective disorder. In Model 2, to distinguish the effect of in utero exposure to antidepressants from the effect of having a parent with a disorder requiring antidepressant medication, we estimated the risk of ASD and $\mathrm{CA}$ in the offspring of fathers who used antidepressant medication during the pregnancy, regardless of maternal use of antidepressant medication. In this analysis, children who could not be linked to a father were excluded $(n=14,091)$. We repeated the analysis, including only fathers with a registrybased diagnosis of affective disorder prior to the pregnancy. In Model 3, we estimated aHRs in a sibling design. We restricted the cohort to include families with at least two full siblings and with at least one of the siblings having been diagnosed with ASD. The aHR for the association between antidepressant exposure and ASD was estimated using stratified Cox regression, with separate diagnostic baseline hazard rates for each family. In the sibling analyses, adjustment for the increasing autism prevalence was achieved by including for the birth date a cubic spline with ten knots. ${ }^{42}$

Finally, to further assess the importance of the main indication for AD use, we estimated the aHR for ASD in children of mothers with a registry-based diagnosis of affective disorder compared with children of mothers with no such diagnosis, regardless of exposure to antidepressants. We repeated this analysis separately in women exposed and not exposed to $\mathrm{AD}$ during pregnancy.

\section{Results \\ Main analysis: use of antidepressant medication in mothers}

The study cohort comprised 655,615 children of 428,407 mothers. During the study period, the overall prevalence of ASD was $1.5 \%$ (95\% confidence interval [CI] 1.5-1.6; 5,437 children), and $0.5 \%$ for CA (95\% CI 0.5-0.5; 2,067 children). The average age at ASD diagnosis was 6.7 years (range 0.2-13.8, median 6.3). The average age at CA diagnosis was 5.7 years (range $0.3-13.8$, median 5.1). The mean age of children at end of follow-up was 8.8 years (range $0-14$, median 8.9). Characteristics of study participants are shown in Table 1 .

We identified 8,833 out of 655,615 children (1.3\%) exposed to antidepressant drugs during pregnancy. Among 5,437 children with ASD, 104 (1.9\%) were exposed to antidepressants. The number of children exposed to antidepressant drugs during pregnancy increased over time (Figure 1). For most children $(80.1 \%)$ of women who filled a prescription of antidepressants during pregnancy, the mother had no registrybased diagnosis of affective disorder (Table 1).

Children exposed to any kind of antidepressant during pregnancy had a 50\% higher risk for ASD (aHR $=1.5 ; 95 \% \mathrm{CI}$ 1.2-1.9) compared with those not exposed $(n=646,782)$. The risk for CA was smaller and not statistically significant $(\mathrm{aHR}=1.3$; 95\% CI 0.9-1.8). The risk did not vary by type of antidepressant, but statistical precision was low for SNRI and TCA (Table 2). The results were essentially unchanged after excluding 25,619 children with congenital birth defects (ASD aHR $=1.6 ; 95 \% \mathrm{CI}$ 1.3-1.9 and CA aHR =1.3; 95\% CI 0.9-1.9).

Some women may have filled a prescription just before the exposure window but took the medicine during the exposure period. Extending the exposure window to 60, 90, and 180 days prior to conception did not markedly change results (results not shown). The results also remained virtually unchanged when we restricted the analysis to women who 
Table I Characteristics of study participants

\begin{tabular}{|c|c|c|c|c|c|}
\hline Characteristic & $\begin{array}{l}\text { AD-exposed } \\
n=8,833\end{array}$ & (\%) & $\begin{array}{l}\text { AD-not exposed } \\
n=646,782\end{array}$ & (\%) & $P$-value ${ }^{\mathrm{d}}$ \\
\hline Maternal age at conception & & & & & $<0.001$ \\
\hline$<21$ years & 373 & 4.2 & 25,869 & 4.0 & \\
\hline $2 \mathrm{I}-25$ years & $\mathrm{I}, 564$ & 17.7 & 125,783 & 19.4 & \\
\hline $26-30$ years & 3,044 & 34.5 & 259,853 & 40.2 & \\
\hline $31-35$ years & 2,669 & 30.2 & 178,433 & 27.6 & \\
\hline$\geq 36$ years & $\mathrm{I}, 183$ & 13.4 & 56,844 & 8.8 & \\
\hline Paternal age at conception & & & & & $<0.001$ \\
\hline$<25$ years & $|, 07|$ & 12.1 & 75,696 & 11.7 & \\
\hline $26-30$ years & 2,388 & 27.0 & 211,695 & 32.7 & \\
\hline $31-35$ years & 2,587 & 29.3 & 209,555 & 32.4 & \\
\hline$\geq 36$ years & 2,371 & 26.8 & 136,072 & 21.0 & \\
\hline Data missing & 416 & 4.7 & 13,764 & 2.1 & \\
\hline Parental psychiatric history ${ }^{\mathrm{a}}$ & & & & & $<0.001$ \\
\hline Yes & 1,897 & 21.5 & 17,853 & 2.8 & \\
\hline No & 6,523 & 73.8 & $6|5,25|$ & 95.1 & \\
\hline Data missing & 413 & 4.7 & 13,678 & 2.1 & \\
\hline Gestational age at birth & & & & & $<0.001$ \\
\hline$<28$ weeks & 17 & 0.2 & 1,215 & 0.2 & \\
\hline 28-3I weeks & 99 & I.I & 4,526 & 0.7 & \\
\hline $32-36$ weeks & 723 & 8.2 & 35,870 & 5.5 & \\
\hline$\geq 37$ weeks & 7,994 & 90.5 & $605,|7|$ & 93.6 & \\
\hline Birth weight & & & & & $<0.001$ \\
\hline$<2,500 \mathrm{~g}$ & 631 & 7.1 & 31,640 & 4.9 & \\
\hline $2,500-2,999 \mathrm{~g}$ & $|, 29|$ & 14.6 & 71,513 & II.I & \\
\hline $3,000-3,499 \mathrm{~g}$ & 2,903 & 32.9 & 196,827 & 30.4 & \\
\hline$\geq 3,500 \mathrm{~g}$ & 3,973 & 45.0 & 343,054 & 53.0 & \\
\hline Data missing & 35 & 0.4 & 3,748 & 0.6 & \\
\hline Sex & & & & & 0.41 \\
\hline Boy & 4,587 & 51.9 & 331,523 & 51.3 & \\
\hline Girl & 4,246 & 48.1 & 315,244 & 48.7 & \\
\hline Data missing & 0 & 0.0 & 15 & 0.0 & \\
\hline Congenital malformation ${ }^{\mathrm{b}}$ & & & & & $<0.001$ \\
\hline Yes & 459 & 5.2 & 25,160 & 3.9 & \\
\hline No & 8,374 & 94.8 & 621,622 & 96.1 & \\
\hline Parity & & & & & 0.70 \\
\hline 0 & 3,780 & 42.8 & 279,513 & 43.2 & \\
\hline$>1$ & 5,053 & 57.2 & 367,263 & 56.8 & \\
\hline Data missing & 0 & 0.0 & 6 & 0.0 & \\
\hline Affective disorder (mother) ${ }^{c}$ & & & & & $<0.001$ \\
\hline Yes & 1,756 & 19.9 & 4,324 & 0.7 & \\
\hline No & 7,077 & 80.1 & 642,458 & 99.3 & \\
\hline Affective disorder (father) ${ }^{c}$ & & & & & $<0.001$ \\
\hline Yes & 159 & 1.8 & 3,195 & 0.5 & \\
\hline No & 8,261 & 93.5 & 629,909 & 97.4 & \\
\hline Data missing & 413 & 4.7 & 13,678 & 2.1 & \\
\hline \multicolumn{6}{|l|}{ Autism spectrum disorder } \\
\hline Yes & 104 & 1.2 & 5,333 & 0.8 & \\
\hline No & 8,729 & 98.8 & 641,449 & 99.2 & \\
\hline \multicolumn{6}{|l|}{ Childhood autism } \\
\hline Yes & 37 & 0.4 & 2,030 & 0.3 & \\
\hline No & 8,796 & 99.6 & 644,752 & 99.7 & \\
\hline
\end{tabular}

Notes: aOne or both parents diagnosed with a psychiatric disorder before birth of the child (except maternal affective disorder) (ICD-8: 290-3I5 and ICD-I0: All F-codes);

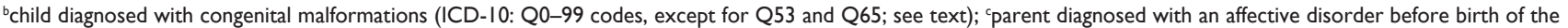
child (ICD-8: 296.09, 296.19, 296.29, 296.39, 296.99, 298.09, 298.19, 300.49, 301.19 and ICD-10: F30-F34 and F38-F39); 'test for no association between characteristic and exposure group.

Abbreviations: $A D$, antidepressants; $n$, number. 
Table 2 Association between maternal use of antidepressants during pregnancy, autism spectrum disorder, and childhood autism in the child, compared with children who were not exposed

\begin{tabular}{|c|c|c|c|c|c|}
\hline AD exposure & Number & $\begin{array}{l}\text { Person years } \\
\text { at risk }\end{array}$ & $\begin{array}{l}\text { Autism spectrum } \\
\text { disorder } \mathrm{n}(\%)\end{array}$ & $\begin{array}{l}\text { Crude HR } \\
(95 \% \mathrm{Cl})\end{array}$ & $\begin{array}{l}\text { Adjusted } \mathbf{H R}^{\mathrm{a}} \\
(95 \% \mathrm{Cl})\end{array}$ \\
\hline \multicolumn{6}{|c|}{ Autism spectrum disorder } \\
\hline Exposed to AD & 8,833 & 65,234 & $104(1.2)$ & I.8 (I.5-2.2) & $1.5(1.2-1.9)$ \\
\hline Exposed to SSRI & 7,506 & 55,015 & $91(1.2)$ & $1.9(1.5-2.4)$ & $1.6(1.3-2.0)$ \\
\hline Exposed to SNRI & 673 & 4,463 & $7(1.0)$ & $1.9(0.9-4.0)$ & $1.7(0.8-3.5)$ \\
\hline Exposed to TCA & 642 & 5,387 & $9(1.4)$ & $1.8(0.95-3.5)$ & $1.5(0.8-2.9)$ \\
\hline Not exposed to AD & 646,782 & $5,733,033$ & $5,333(0.8)$ & $\mathrm{I} .0$ (ref) & 1.0 (ref) \\
\hline AD exposure & Number & $\begin{array}{l}\text { Person years } \\
\text { at risk }\end{array}$ & $\begin{array}{l}\text { Childhood autism } \\
\text { n (\%) }\end{array}$ & $\begin{array}{l}\text { Crude HR } \\
(95 \% \mathrm{Cl})\end{array}$ & $\begin{array}{l}\text { Adjusted } \mathbf{H R}^{\mathrm{a}} \\
(95 \% \mathrm{Cl})\end{array}$ \\
\hline \multicolumn{6}{|l|}{ Childhood autism } \\
\hline Exposed to AD & 8,833 & 65,390 & $37(0.4)$ & $1.5(I .1-2.1)$ & $1.3(0.9-1.8)$ \\
\hline Exposed to SSRI & 7,506 & 55,142 & $34(0.5)$ & $1.6(1.1-2.3)$ & $1.4(0.9-2.0)$ \\
\hline Exposed to SNRI & 673 & 4,481 & I $(0.1)$ & NA & NA \\
\hline Exposed to TCA & 642 & 5,407 & $2(0.3)$ & NA & NA \\
\hline Not exposed to $A D$ & 646,782 & $5,743,343$ & $2,030(0.3)$ & I.0 (ref) & 1.0 (ref) \\
\hline
\end{tabular}

Notes: aHazard ratios were adjusted for maternal age at conception, paternal age at conception, parental psychiatric history (except maternal affective disorder), gestational age, birth weight, sex, and parity.

Abbreviations: AD, antidepressant drugs; HR, hazard ratio; $n$, number; SSRI, selective serotonin reuptake inhibitor; SNRI, serotonin-norepinephrine reuptake inhibitors; TCA, tricyclic antidepressants; ref, reference; NA, not applicable; $\mathrm{Cl}$, confidence interval.

filled more than one prescription of antidepressant medication during the exposure window (ASD aHR $=1.7 ; 95 \% \mathrm{CI}$ 1.3-2.2 and CA aHR $=1.4 ; 95 \%$ CI 1.0-2.2).

\section{Dose-response}

The aHR for ASD was increased in children exposed to a low (aHR $=1.3 ; 95 \%$ CI 1.0-1.8) as well as a high mean dose of antidepressant (aHR $=1.8 ; 95 \%$ CI 1.3-2.4) compared with those unexposed. Results were similar for SSRI exposure (low mean dose: $\mathrm{aHR}=1.4 ;$ 95\% CI 1.0-1.9) (high mean dose: $\mathrm{aHR}=1.8$; 95\% CI 1.3-2.4). The numbers were too small to perform doseresponse analyses for exposure to TCA and SNRI.

\section{Timing of exposure}

Risk estimates for children exposed early in pregnancy were similar to those only exposed later in pregnancy, although only the first trimester exposure reached statistical significance: for ASD aHR sst trimester $=1.5\left(95 \%\right.$ CI 1.2-1.9); aHR $_{2 \text { nd }+3 \text { rd trimester }}$ only $=1.5(95 \%$ CI $0.8-2.7)$. Trends for exposure to SSRI by pregnancy period were similar: ASD $\mathrm{aHR}_{1 \text { st trimester }}=1.6(95 \%$ CI 1.3-2.0); $\mathrm{aHR}_{2 \text { nd }+3 \mathrm{rd} \text { trimester only }}=1.4$ (95\% CI 0.7-2.7). The number of children exposed to both SNRI and TCA was too small for analysis.

\section{Assessment of confounding by indication Model I: analyses restricted to mothers with affective disorder}

Overall, 1.1\% (95\% CI 1.1-1.1) of mothers in the cohort were registered with an affective disorder in the DPCR.
The corresponding estimate was $1.5 \%$ (95\% CI 1.2-1.9) among mothers of children with ASD. Compared with results from the main analysis, ASD risk estimates were lower and not statistically significant in analysis restricted to 6,080 children of mothers with a registry-based diagnosis of affective disorder prior to birth of the child: $\mathrm{AD}$ aHR $=1.2$ (95\% CI 0.7-2.1); SSRI aHR =1.4 (95\% CI 0.8-2.4). In this subgroup, no association was found between prenatal exposure to antidepressant medication and risk of $\mathrm{CA}$ (Table 3).

The risks of ASD after exposure during the first trimester were also somewhat reduced and not statistically significant when analyses were restricted to women with a diagnosis of affective disorder: $\mathrm{AD} \mathrm{aHR}_{1 \mathrm{st} \text { trimester }}=1.3$ (95\% CI 0.7-2.3); $\mathrm{SSRI}_{\mathrm{aHR}}$ st trimester $=1.4$ (95\% CI 0.8-2.6). Sample sizes were too small for analysis of the exposure to both SNRI and TCA.

\section{Model 2: use of antidepressant medication in fathers} Children of fathers who used an antidepressant while the mother was pregnant had the same risk of ASD as children of fathers who did not use antidepressants (Table 4). Paternal use of SSRI was, however, associated with a statistically significant higher risk of ASD in the child compared with no antidepressant use: $\mathrm{aHR}=1.3$ (95\% CI 1.0-1.6) (Table 4). When restricting the analysis to children of fathers with a registry-based diagnosis of affective disorder, the risk from paternal antidepressant use was not significantly increased (data not shown). Paternal and maternal use of antidepressant 
Table 3 Association between maternal antidepressant exposure and autism spectrum disorder and childhood autism in children born to mothers with a hospital-diagnosed affective disorder, in comparison with children not exposed

\begin{tabular}{|c|c|c|c|c|}
\hline AD exposure & $\begin{array}{l}\text { Live births } \\
\text { (n) }\end{array}$ & $\begin{array}{l}\text { Autism spectrum } \\
\text { disorder } \mathrm{n}(\%)\end{array}$ & $\begin{array}{l}\text { Crude HR } \\
(95 \% \mathrm{Cl})\end{array}$ & $\begin{array}{l}\text { Adjusted } \mathrm{HR}^{\mathrm{a}} \\
(95 \% \mathrm{Cl})\end{array}$ \\
\hline \multicolumn{5}{|c|}{ Autism spectrum disorder } \\
\hline Exposed to AD & $\mathrm{I}, 756$ & $24(1.4)$ & $1.4(0.8-2.3)$ & $1.2(0.7-2.1)$ \\
\hline Exposed to SSRI & $\mathrm{I}, 475$ & $22(1.5)$ & $1.6(0.9-2.6)$ & $1.4(0.8-2.4)$ \\
\hline Exposed to SNRI & 203 & $4(2.0)$ & NA & NA \\
\hline Exposed to TCA & 163 & $3(1.8)$ & NA & NA \\
\hline Not exposed to AD & 4,324 & $48(I . I)$ & I.0 (ref) & I.0 (ref) \\
\hline AD exposure & $\begin{array}{l}\text { Live births } \\
(\mathrm{n})\end{array}$ & $\begin{array}{l}\text { Childhood autism } \\
\text { n (\%) }\end{array}$ & $\begin{array}{l}\text { Crude HR } \\
(95 \% \mathrm{Cl}) \\
\end{array}$ & $\begin{array}{l}\text { Adjusted } \mathrm{HR}^{\mathrm{a}} \\
(95 \% \mathrm{Cl})\end{array}$ \\
\hline \multicolumn{5}{|l|}{ Childhood autism } \\
\hline Exposed to AD & $\mathrm{I}, 756$ & $7(0.4)$ & $0.9(0.4-2.2)$ & $0.8(0.3-2.1)$ \\
\hline Exposed to SSRI & $\mathrm{I}, 475$ & $7(0.5)$ & I.I (0.5-2.7) & $1.0(0.4-2.6)$ \\
\hline Exposed to SNRI & 203 & $0(0.0)$ & NA & NA \\
\hline Exposed to TCA & 163 & $0(0.0)$ & NA & NA \\
\hline Not exposed to AD & 4,324 & $20(0.5)$ & I.0 (ref) & I.0 (ref) \\
\hline
\end{tabular}

Notes: a Hazard ratios were adjusted for maternal age at conception, paternal age at conception, parental psychiatric history (except maternal affective disorder), gestational age, birth weight, sex, and parity.

Abbreviations: AD, antidepressant drugs; HR, hazard ratio; $n$, number; SSRI, selective serotonin reuptake inhibitor; SNRI, serotonin-norepinephrine reuptake inhibitors; TCA, tricyclic antidepressants; NA, not applicable; ref, reference; $\mathrm{Cl}$, confidence interval.

medication was not correlated (Spearman correlation coefficient 0.04).

\section{Model 3: sibling analysis}

We identified 177,552 families with at least two full siblings (387,494 children), including 6,142 children from families having at least one child with ASD. We found a similar risk of ASD in children exposed to antidepressant medication (aHR $=1.1 ; 95 \%$ CI $0.5-2.3$ ) and specifically to SSRI
(aHR $=0.9 ; 95 \%$ CI 0.4-2.0) when compared with their unexposed siblings (Table 5). Sample sizes were too small to perform analyses for CA or for both SNRI and TCA exposure.

Effect of diagnosis of affective disorder in the mother The aHR of ASD in children of women with a registry-based diagnosis of affective disorder was slightly but not significantly increased compared with children of women with no

Table 4 Association between the use of antidepressants in fathers during pregnancy and autism spectrum disorder and childhood autism in the child in comparison with children of fathers not using antidepressants during pregnancy

\begin{tabular}{|c|c|c|c|c|c|}
\hline AD exposure & Number & $\begin{array}{l}\text { Person-years } \\
\text { at risk }\end{array}$ & $\begin{array}{l}\text { Autism spectrum } \\
\text { disorder } \mathbf{n}(\%)\end{array}$ & $\begin{array}{l}\text { Crude HR } \\
(95 \% \mathrm{Cl})\end{array}$ & $\begin{array}{l}\text { Adjusted } \mathbf{H R}^{\mathrm{a}} \\
(95 \% \mathrm{Cl})\end{array}$ \\
\hline \multicolumn{6}{|c|}{ Autism spectrum disorder } \\
\hline Exposed to AD & 11,388 & 88,921 & $100(0.9)$ & $1.3(1.04-1.5)$ & I.I (0.9-I.3) \\
\hline Exposed to SSRI & 7,536 & 59,335 & $76(1.0)$ & I.4 (I.I-I.8) & $1.3(1.002-1.6)$ \\
\hline Exposed to SNRI & 1,065 & 7,718 & $9(0.8)$ & I.3 (0.7-2.6) & I.I (0.6-2.I) \\
\hline Exposed to TCA & I,397 & 11,839 & $8(0.6)$ & $0.7(0.4-1.5)$ & $0.6(0.3-1.3)$ \\
\hline Not exposed to AD & 630,136 & $5,587,702$ & $5,154(0.8)$ & 1.0 (ref) & 1.0 (ref) \\
\hline AD exposure & Number & $\begin{array}{l}\text { Person-years } \\
\text { at risk }\end{array}$ & $\begin{array}{l}\text { Childhood autism } \\
\text { number (\%) }\end{array}$ & $\begin{array}{l}\text { Crude HR } \\
(95 \% \mathrm{Cl}) \\
\end{array}$ & $\begin{array}{l}\text { Adjusted } \mathrm{HR}^{\mathrm{a}} \\
(95 \% \mathrm{CI}) \\
\end{array}$ \\
\hline \multicolumn{6}{|l|}{ Childhood autism } \\
\hline Exposed to AD & 11,388 & 89,108 & $40(0.4)$ & $1.2(0.9-1.7)$ & $1.0(0.7-1.4)$ \\
\hline Exposed to SSRI & 7,536 & 59,485 & $28(0.4)$ & $1.3(0.9-1.9)$ & I.I (0.7-I.6) \\
\hline Exposed to SNRI & 1,065 & 7,733 & $4(0.4)$ & NA & NA \\
\hline Exposed to TCA & $\mathrm{I}, 397$ & 11,845 & $5(0.4)$ & I.2 (0.5-2.8) & $1.0(0.4-2.4)$ \\
\hline Not exposed to AD & 630,136 & $5,597,647$ & I,959 (0.3) & I.0 (ref) & 1.0 (ref) \\
\hline
\end{tabular}

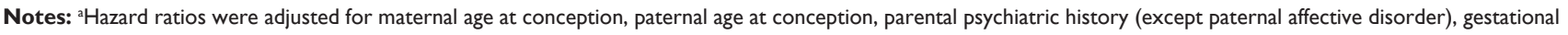
age, birth weight, sex, and parity.

Abbreviations: AD, antidepressant drugs; HR, hazard ratio; n, number; SSRI, selective serotonin reuptake inhibitor; SNRI, serotonin-norepinephrine reuptake inhibitors; TCA, tricyclic antidepressants; NA, not applicable; ref, reference; $\mathrm{Cl}$, confidence interval. 
Table 5 Association between maternal use of antidepressants and autism spectrum disorder in exposed and not exposed siblings from 2,765 families with at least one child with autism spectrum disorder

\begin{tabular}{|c|c|c|c|c|c|}
\hline AD exposure & $\begin{array}{l}\text { Number of } \\
\text { children }\end{array}$ & $\begin{array}{l}\text { Person-years } \\
\text { at risk }\end{array}$ & $\begin{array}{l}\text { Autism spectrum } \\
\text { disorder } \mathrm{n}(\%)\end{array}$ & $\begin{array}{l}\text { Crude HR } \\
(95 \% \mathrm{Cl})\end{array}$ & $\begin{array}{l}\text { Adjusted HR } \text { HR }^{\mathrm{a}} \\
(95 \% \mathrm{Cl})\end{array}$ \\
\hline Exposed to $A D^{b}$ & 96 & 681.0 & $37(38.5)$ & $0.8(0.4-1.6)$ & I.I (0.5-2.3) \\
\hline Not exposed to AD & 6,046 & $47,288.6$ & $2,850(47.1)$ & I.0 (ref) & I.0 (ref) \\
\hline SSRI exposurec & $\begin{array}{l}\text { Number of } \\
\text { children }\end{array}$ & $\begin{array}{l}\text { Person years } \\
\text { at risk }\end{array}$ & $\begin{array}{l}\text { Autism spectrum } \\
\text { disorder } \mathrm{n}(\%)\end{array}$ & $\begin{array}{l}\text { Crude HR } \\
(95 \% \mathrm{Cl})\end{array}$ & $\begin{array}{l}\text { Adjusted HR } \text { Ha }^{\text {ad }}(95 \% \mathrm{Cl}) \\
\end{array}$ \\
\hline \multicolumn{6}{|c|}{ Association between the use of SSRI and ASD in siblings from 2,765 families with at least one child with ASD } \\
\hline Exposed to SSRI & 81 & 579.0 & $30(37.0)$ & $0.7(0.3-1.5)$ & $0.9(0.4-2.0)$ \\
\hline Not exposed to SSRI & 6,036 & $47,211.2$ & $2,845(47.1)$ & I.0 (ref) & I.0 (ref) \\
\hline
\end{tabular}

Notes: a Hazard ratios were adjusted for maternal age at conception, paternal age at conception, gestational age, birth weight, sex, and parity; ${ }^{\mathrm{b}} 58$ families had two or more children who were discordant for AD exposure as well as ASD diagnosis; 'children exposed only to AD other than SSRI were excluded from this analysis. Families who only had one child in the analysis after this were excluded.

Abbreviations: AD, antidepressant drugs; ASD, autism spectrum disorder; HR, hazard ratio; $n$, number; (ref), reference; SSRI, selective serotonin reuptake inhibitor; SNRI, serotonin-norepinephrine reuptake inhibitors; TCA, tricyclic antidepressants; $\mathrm{Cl}$, confidence interval.

registry-based diagnosis of affective disorder, regardless of AD use: ASD aHR $=1.2$ (95\% CI 1.0-1.6). Similar results were found when restricting the analysis to women who did not fill a prescription for antidepressants during pregnancy; the aHR of ASD in children born to women with a registrybased diagnosis of affective disorder $(n=4,324)$ was slightly but not significantly increased compared with children born to women with no registry based diagnosis: aHR $=1.2(95 \% \mathrm{CI}$ 0.9-1.6). In contrast, when restricting the analysis to women who filled antidepressant prescriptions during pregnancy, there was no ASD risk effect of a registry-based diagnosis of affective disorder: aHR $=1.0(95 \%$ CI $0.6-1.8)$.

\section{Discussion}

We found the association between prenatal maternal antidepressant use and later ASD in the child to be lower than reported in recent epidemiologic studies. ${ }^{27,28}$ The association was found for high as well as for low dose levels, and risk estimates were comparable regardless of timing of exposure.

Because parental psychiatric disorder in itself carries a risk of ASD in the offspring, ${ }^{29,30}$ we attempted in further analyses to separate the effect of medication from that of the underlying indication for treatment by restricting the analysis to children of mothers with a history of affective disorder. In the latter subsample, the association between antidepressant exposure and later offspring ASD was even smaller and not statistically significant: aHR 1.2 (95\% CI 0.7-2.1). Second, paternal antidepressant use during the time of pregnancy was not associated with an increased risk of autism spectrum disorders, except for a $30 \%$ increase when the fathers took SSRI specifically, indicating that lifestyle or genetic factors associated with paternal indication for antidepressant medication may be less of a risk compared with maternal indications.
Finally, we performed a sibling analysis attempting to remove the effects of shared familial risk factors and found no difference in the risk of ASD between full siblings who were exposed and those unexposed to antidepressants during their mother's pregnancy.

The association found in multivariate and stratified analyses was found for high- as well as for low-dose levels, and risk estimates were comparable regardless of timing of exposure.

\section{Comparison with previous studies}

Studies in rodents suggest that neonatal exposure to SSRI or other serotonergic agonists have a profound impact on serotonin circuitry ${ }^{43}$ and social behavior. ${ }^{44}$ To our knowledge, only two previous human studies have examined the association between antidepressant medication during pregnancy and ASD. In a study of 298 children with ASD, including 20 children exposed to antidepressant medication before birth, and 1,507 controls, including 50 children exposed to antidepressant medication before birth, Croen et $\mathrm{al}^{28}$ found a 2- to 2.6 -fold increased risk in offspring of women taking antidepressant medication during the year before delivery, after controlling for psychiatric history in the mother. However, the risk observed in analysis restricted to women with a history of depression, thus more fully controlling for maternal psychiatric history, was lower and not significantly elevated. It is noteworthy that the prevalence of antidepressant use (3.3\% in controls, $6.7 \%$ in cases) or a diagnosis of depression ( $2.7 \%$ in controls, $3.4 \%$ in cases) was higher in the Croen et $\mathrm{al}^{28}$ study compared with that in our study cohort (AD use: $1.3 \%$ in the entire cohort, $1.9 \%$ in children with ASD; maternal registry diagnosis of affective disorder: $1.1 \%$ in the entire cohort, $1.5 \%$ in mothers of children with ASD). This may reflect differences in 
the two study populations related to access to mental health diagnosis or to treatment that may contribute to the different study results. Recently, Rai et $\mathrm{al}^{27}$ compared 1,679 children with ASD (21 exposed to antidepressants before birth) with 16,845 controls (98 exposed to antidepressants before birth) in a nested case-control study and demonstrated an almost five-fold increased risk of ASD in children born to women with a history of depression and antidepressant use in pregnancy, and a two-fold increase in children born to women with a history of depression but no antidepressant use in pregnancy. However, these authors acknowledged that the use of antidepressants during pregnancy might be an indication for current depression; thus, confounding by lifestyle or other factors related to current affective disorder is possible. Contrary to Rai et al, ${ }^{27}$ we found that the risk of ASD associated with maternal history of affective disorder was only slightly and not significantly elevated. We found no increased risk associated with a history of affective disorder in analysis restricted to women taking antidepressant drugs. Thus, our findings suggest that other factors in addition to severe affective disorder may act as confounding factors.

Taken as a whole, our results suggest that the association between antidepressant exposure and later autism demonstrated in previous studies may, all or in part, result from confounding by the underlying maternal indication for antidepressant use or other unmeasured factors related to maternal disease during pregnancy on ASD risk. Previous studies did not include a sibling analysis, which would have allowed for more control of otherwise unmeasured confounding factors related to the family. Because we did not find the risk of ASD associated with a registry-based diagnosis of affective disorder, confounding factors may include other indications for antidepressant use, genetic, or lifestyle factors not fully accounted for by diagnosis of affective disorder or other psychiatric disorders in the parents associated with antidepressant use.

The apparent residual confounding may partly reflect genetic susceptibility to both autism and the underlying disorder indicating treatment. Our analyses of antidepressant use in the father showed only a small increase in risk of ASD in the offspring after SSRI exposure, which is in line with findings from Rai et al. ${ }^{27}$ Therefore, a possible genetic contribution to the association between AD use and autism might come mostly from the mother. One theoretical possibility is that the fragile $\mathrm{X}$ premutation carrier state is associated with increased anxiety and depression in the mother ${ }^{45}$ and an increased risk of fragile $\mathrm{X}$ syndrome, and therefore, with autism in the offspring. ${ }^{46}$

\section{Strengths and weaknesses of the data}

The present study has several strengths in relation to the population studied. This population-based cohort included all children born alive in Denmark between 1996 and 2006, with follow-up data for up to 13 years. Less than $3 \%$ of the cohort emigrated or died. Misclassification of exposure or outcome is mitigated by the fact that health care in Denmark is free and universally available.

Our study has some limitations, but these are largely mitigated by data from other studies. We assumed that persons who filled a prescription for antidepressants also ingested the medication. This may not always be the case: in fact, pregnancy is reportedly a frequent reason for discontinuing treatment. ${ }^{47-49}$ However, one Danish study showed relatively high compliance ( $80 \%$ ) for antidepressant medication prescribed to pregnant women in Denmark. ${ }^{50}$ Importantly, sensitivity analyses including only women who filled at least two prescriptions during pregnancy and analyses using different exposure windows did not change results markedly, and risk estimates for women only exposed in second and third trimester were similar to overall risk estimates. However, the number of women exposed only in the second and third trimesters was low, and misclassification of timing of the exposure may have occurred when a prescription was filled in the first trimester and the medication ingested later in pregnancy.

The prescription database does not include medication administered during inpatient admissions. Antidepressants are, however, used for long-term treatment and a psychiatric disorder severe enough to prompt inpatient hospitalization would usually lead to continued treatment after discharge. The number of women with prescriptions for both SNRIs and TCAs was low, thus preventing in-depth analysis of the effects of these drugs. The estimated dose may be prone to error if the dosage was changed during pregnancy. Misclassification of the timing of conception is likely to be small. $^{51,52}$

The outcome of ASD or CA is based on data from the Danish Psychiatric Central Register. The registry is nationwide and includes diagnoses from all in- and out-patient admissions to psychiatric hospitals and hospital-based outpatient clinics. The DPCR has a high validity for $\mathrm{CA} .{ }^{40}$ Other ASD diagnoses have not been validated, but the quality is expected to be high. Some cases of ASD may be diagnosed by a private child psychiatrist or remain undiagnosed. However, our observed prevalence of ASDs was 1.5\%, an estimate similar to the prevalence of $1.1 \%$ in US children aged $3-17$ years. ${ }^{53}$ 
Parents with less severe forms of psychiatric disorders treated in primary care are not registered in the DPCR. Only $19.9 \%$ of mothers filling a prescription for antidepressants during the exposure window had a registry-based diagnosis of affective disorder. The remaining $80.1 \%$ of women will either have a prescription for antidepressants because of other disorders such as anxiety or adjustment disorders or will receive treatment from their general practitioner or private psychiatrist; these practitioners do not report diagnoses to the DPCR. This group of women may differ from women with a registry-based diagnosis of affective disorder, although any potential differences did not lead to a difference in ASD risk. In women with $\mathrm{AD}$ use, the risk for ASD in the offspring was similar in women with and without a registry-based diagnosis of affective disorder.

A range of lifestyle factors may influence the intrauterine environment and increase the risk for adverse outcomes. We did not have information about specific lifestyle factors, but in both the analysis restricted to women with affective disorders and in the sibling design analysis, we attempted to adjust for such unmeasured factors related to ASD.

The discordant sibling analysis adjusts for all factors that were shared within the family. The discordant sibling exposure analysis may be biased by nonshared confounders associated with exposure, because the siblings will tend to be also discordant for confounding variables. ${ }^{54}$ To our knowledge, no previous study which examined the risk of ASD after prenatal exposure to antidepressants used a discordant sibling design.

\section{Conclusion}

The association between ASD in the offspring and antidepressant drug use during pregnancy observed overall was reduced and no longer significant when analyzing children of women with a diagnosis of affective disorder or when studying the risk in a sibling design. Thus, confounding by the effects of maternal disorder or by unmeasured factors related to maternal disorder during pregnancy may at least partly explain the overall association rather than a direct drug effect. Treatment and counseling of pregnant women with an affective disorder should take into account known harmful effects of untreated affective disorder, as well as known and potential harmful effects of antidepressant medication.

\section{Disclosure}

The findings and conclusions in this report are those of the authors and do not necessarily represent the official position of the Centers for Disease Control and Prevention.
Jakob Christensen received honoraria from giving lectures and serving on the scientific advisory board of UCB Nordic and Eisai $\mathrm{AB}$, and received funding for a trip from $\mathrm{UCB}$ Nordic. The other authors have no conflicts to declare in this study.

\section{References}

1. Andrade SE, Raebel MA, Brown J, et al. Use of antidepressant medications during pregnancy: a multisite study. Am J Obstet Gynecol. 2008;198(2):194. e1-194. e5.

2. Alwan S, Reefhuis J, Rasmussen SA, Friedman JM. Patterns of antidepressant medication use among pregnant women in a United States population. J Clin Pharmacol. 2011;51(2):264-270.

3. El Marroun H, Jaddoe VW, Hudziak JJ, et al. Maternal use of selective serotonin reuptake inhibitors, fetal growth, and risk of adverse birth outcomes. Arch Gen Psychiatry. 2012;69(7):706-714.

4. Munk-Olsen T, Gasse C, Laursen TM. Prevalence of antidepressant use and contacts with psychiatrists and psychologists in pregnant and postpartum women. Acta Psychiatr Scand. 2012;125(4):318-324.

5. Kieler H, Artama M, Engeland A, et al. Selective serotonin reuptake inhibitors during pregnancy and risk of persistent pulmonary hypertension in the newborn: population based cohort study from the five Nordic countries. BMJ. 2012;344:d8012.

6. Pedersen LH, Henriksen TB, Olsen J. Fetal exposure to antidepressants and normal milestone development at 6 and 19 months of age. Pediatrics. 2010;125:e600-e608.

7. Casper RC, Fleisher BE, Lee-Ancajas JC, et al. Follow-up of children of depressed mothers exposed or not exposed to antidepressant drugs during pregnancy. J Pediatr. 2003;142(4):402-408.

8. Udechuku A, Nguyen T, Hill R, Szego K. Antidepressants in pregnancy: a systematic review. Aust N Z J Psychiatry. 2010;44(11):978-996.

9. Oberlander TF, Grunau RE, Fitzgerald C, Papsdorf M, Rurak D, Riggs W. Pain reactivity in 2-month-old infants after prenatal and postnatal serotonin reuptake inhibitor medication exposure. Pediatrics. 2005;115(2):411-425.

10. Casper RC, Gilles AA, Fleisher BE, Baran J, Enns G, Lazzeroni LC. Length of prenatal exposure to selective serotonin reuptake inhibitor (SSRI) antidepressants: effects on neonatal adaptation and psychomotor development. Psychopharmacology (Berl). 2011;217(2):211-219.

11. Pedersen LH, Henriksen TB, Vestergaard M, Olsen J, Bech BH. Selective serotonin reuptake inhibitors in pregnancy and congenital malformations: population based cohort study. BMJ. 2009;339:b3569.

12. Misri S, Reebye $P$, Kendrick $K$, et al. Internalizing behaviors in 4-year-old children exposed in utero to psychotropic medications. Am J Psychiatry. 2006;163(6):1026-1032.

13. Oberlander TF, Reebye P, Misri S, Papsdorf M, Kim J, Grunau RE. Externalizing and attentional behaviors in children of depressed mothers treated with a selective serotonin reuptake inhibitor antidepressant during pregnancy. Arch Pediatr Adolesc Med. 2007;161(1):22-29.

14. Nulman I, Koren G, Rovet J, et al. Neurodevelopment of children following prenatal exposure to venlafaxine, selective serotonin reuptake inhibitors, or untreated maternal depression. Am J Psychiatry. 2012;169(11):1165-1174.

15. Nulman I, Rovet J, Stewart DE, et al. Child development following exposure to tricyclic antidepressants or fluoxetine throughout fetal life: a prospective, controlled study. Am J Psychiatry. 2002;159(11): 1889-1895.

16. Nordeng H, van Gelder MM, Spigset O, Koren G, Einarson A, EberhardGran M. Pregnancy outcome after exposure to antidepressants and the role of maternal depression: results from the Norwegian Mother and Child Cohort Study. J Clin Psychopharmacol. 2012;32(2):186-194.

17. Vasilakis-Scaramozza C, Aschengrau A, Cabral H, Jick SS. Antidepressant use during early pregnancy and the risk of congenital anomalies. Pharmacotherapy. 2013;33(7):693-700. 
18. Keyes KM, Susser E, Cheslack-Postava K, Fountain C, Liu K, Bearman PS. Cohort effects explain the increase in autism diagnosis among children born from 1992 to 2003 in California. Int J Epidemiol. 2012;41(2):495-503.

19. Lauritsen MB, Pedersen CB, Mortensen PB. The incidence and prevalence of pervasive developmental disorders: a Danish population-based study. Psychol Med. 2004;34(7):1339-1346.

20. Hallmayer J, Cleveland S, Torres A, et al. Genetic heritability and shared environmental factors among twin pairs with autism. Arch Gen Psychiatry. 2011;68(11):1095-1102.

21. Tran PL, Lehti V, Lampi KM, et al. Smoking during pregnancy and risk of autism spectrum disorder in a Finnish National Birth Cohort. Paediatr Perinat Epidemiol. 2013;27:266-274.

22. Atladottir HO, Thorsen P, Ostergaard L, et al. Maternal infection requiring hospitalization during pregnancy and autism spectrum disorders. J Autism Dev Disord. 2010;40(12):1423-1430.

23. Brown AS, Sourander A, Hinkka-Yli-Salomaki S, McKeague IW, Sundvall J, Surcel HM. Elevated maternal C-reactive protein and autism in a national birth cohort. Mol Psychiatry. Epub January 22, 2013.

24. Christensen J, Grønborg TK, Sorensen MJ, et al. Prenatal valproate exposure and risk of autism spectrum disorders and childhood autism. JAMA. 2013;309(916):1696-1703.

25. Harrington RA, Lee LC, Crum RM, Zimmerman AW, Hertz-Picciotto I. Serotonin Hypothesis of autism: implications for selective serotonin reuptake inhibitor use during pregnancy. Autism Res. 2013;6(3): 149-168.

26. Whitaker-Azmitia PM. Behavioral and cellular consequences of increasing serotonergic activity during brain development: a role in autism? Int J Dev Neurosci. 2005;23(1):75-83.

27. Rai D, Lee BK, Dalman C, Golding J, Lewis G, Magnusson C. Parental depression, maternal antidepressant use during pregnancy, and risk of autism spectrum disorders: population based case-control study. BMJ. 2013;346:f2059.

28. Croen LA, Grether JK, Yoshida CK, Odouli R, Hendrick V. Antidepressant use during pregnancy and childhood autism spectrum disorders. Arch Gen Psychiatry. 2011;68(11):1104-1112.

29. Larsson HJ, Eaton WW, Madsen KM, et al. Risk factors for autism perinatal factors, parental psychiatric history, and socioeconomic status Am J Epidemiol. 2005;161(10):916-925.

30. Daniels JL, Forssen U, Hultman CM, et al. Parental psychiatric disorders associated with autism spectrum disorders in the offspring. Pediatrics. 2008;121:e1357-e1362.

31. Cohen LS, Altshuler LL, Harlow BL, et al. Relapse of major depression during pregnancy in women who maintain or discontinue antidepressant treatment. JAMA. 2006;295(5):499-507.

32. Bonari L, Pinto N, Ahn E, Einarson A, Steiner M, Koren G. Perinatal risks of untreated depression during pregnancy. Can J Psychiatry. 2004;49(11):726-735.

33. Deave T, Heron J, Evans J, Emond A. The impact of maternal depression in pregnancy on early child development. BJOG. 2008;115(8):1043-1051.

34. Pedersen CB, Gotzsche H, Moller JO, Mortensen PB. The Danish Civil Registration System. A cohort of eight million persons. Dan Med Bull. 2006;53(4):441-449.

35. Kildemoes HW, Sorensen HT, Hallas J. The Danish National Prescription Registry. Scand J Public Health. 2011;39(Suppl 7):38-41.

36. Mors O, Perto GP, Mortensen PB. The Danish Psychiatric Central Research Register. Scand J Public Health. 2011;39(Suppl 7):54-57.

\section{Clinical Epidemiology}

\section{Publish your work in this journal}

Clinical Epidemiology is an international, peer-reviewed, open access journal focusing on disease and drug epidemiology, identification of risk factors and screening procedures to develop optimal preventative initiatives and programs. Specific topics include: diagnosis, prognosis, treatment, screening, prevention, risk factor modification, systematic
37. Knudsen LB, Olsen J. The Danish Medical Birth Registry. Dan Med Bull. 1998;45(3):320-323.

38. Andersen TF, Madsen M, Jorgensen J, Mellemkjoer L, Olsen JH. The Danish National Hospital Register. A valuable source of data for modern health sciences. Dan Med Bull. 1999;46(3):263-268.

39. ATC/DDD Index 2012. WHO Collaborating Centre for Drug Statistics Methodology. Available from: http://www.whocc.no/atc_ddd_index/. Accessed September 29, 2013.

40. Lauritsen MB, Jorgensen M, Madsen KM, et al. Validity of childhood autism in the Danish Psychiatric Central Register: findings from a cohort sample born 1990-1999. J Autism Dev Disord. 2010;40(2): 139-148.

41. Larsen H, Nielsen GL, Bendsen J, Flint C, Olsen J, Sørensen HT. Predictive value and completeness of the registration of congenital abnormalities in three Danish population-based registries. Scand J Public Health. 2003;31(1):12-16.

42. Smith PL. Splines as a useful and convenient statistical tool. The American Statistician. 1979;33(2):57-62.

43. Maciag D, Simpson KL, Coppinger D, et al. Neonatal antidepressant exposure has lasting effects on behavior and serotonin circuitry. Neuropsychopharmacology. 2006;31(1):47-57.

44. McNamara IM, Borella AW, Bialowas LA, Whitaker-Azmitia PM. Further studies in the developmental hyperserotonemia model (DHS) of autism: social, behavioral and peptide changes. Brain Res. 2008;1189: 203-214.

45. Bourgeois JA, Coffey SM, Rivera SM, et al. A review of fragile X premutation disorders: expanding the psychiatric perspective. $J$ Clin Psychiatry. 2009;70(6):852-862.

46. Clifford S, Dissanayake C, Bui QM, Huggins R, Taylor AK, Loesch DZ. Autism spectrum phenotype in males and females with fragile $\mathrm{X}$ full mutation and premutation. J Autism Dev Disord. 2007;37(4): 738-747.

47. Petersen I, Gilbert RE, Evans SJ, Man SL, Nazareth I. Pregnancy as a major determinant for discontinuation of antidepressants: an analysis of data from The Health Improvement Network. J Clin Psychiatry. 2011;72(7):979-985.

48. Bennett IM, Marcus SC, Palmer SC, Coyne JC. Pregnancy-related discontinuation of antidepressants and depression care visits among Medicaid recipients. Psychiatr Serv. 2010;61(4):386-391.

49. Ramos E, Oraichi D, Rey E, Blais L, Berard A. Prevalence and predictors of antidepressant use in a cohort of pregnant women. BJOG 2007;114(9):1055-1064.

50. Olesen C, Sondergaard C, Thrane N, Nielsen GL, de Jong-van den Berg L, Olsen J. Do pregnant women report use of dispensed medications? Epidemiology. 2001;12(5):497-501.

51. Olesen AW, Westergaard JG, Thomsen SG, Olsen J. Correlation between self-reported gestational age and ultrasound measurements. Acta Obstet Gynecol Scand. 2004;83(11):1039-1043.

52. Kristensen J, Langhoff-Roos J, Skovgaard LT, Kristensen FB. Validation of the Danish Birth Registration. J Clin Epidemiol. 1996; 49(8):893-897.

53. Kogan MD, Blumberg SJ, Schieve LA, et al. Prevalence of parentreported diagnosis of autism spectrum disorder among children in the US, 2007. Pediatrics. 2009;124(5):1395-1403.

54. Frisell T, Öberg S, Kuja-Halkola R, Sjölander A. Sibling comparison designs: bias from non-shared confounders and measurement error. Epidemiology. 2012;23(5):713-720.

\section{Dovepress}

reviews, risk \& safety of medical interventions, epidemiology \& biostatical methods, evaluation of guidelines, translational medicine, health policies \& economic evaluations. The manuscript management system is completely online and includes a very quick and fair peer-review system, which is all easy to use. 